\title{
Correlation between adipokines and carotid intima media thickness in a group of obese Romanian children: is small for gestational age status an independent factor for cardiovascular risk?
} Ramona Stroescu' ${ }^{1,2}$, Teofana Bizerea ${ }^{1,2}$, Gabriela Doroş
Monica Marazan', Maria Lesovici' , Otilia Märginean
1 "Louis Turcanu" Emergency Hospital for Children, Timişoara, România

2 "Victor Babes" University of Medicine and Pharmacy,

Timişoara, România

Correspondence to: Ramona Stroescu

"Louis Turcanu" Emergency Hospital for Children Timişoara 300011 - losif Nemoianu 2 Timişoara ramona.giurescu@gmail.com

Received on Nov/3/2015 Accepted on Mar/6/2016

DOI: 10.1590/2359-399700000020

\begin{abstract}
Objective: To investigate the relationship between markers of adiposity and common carotid artery (CIMT) in obese children born small for gestational age (SGA) versus appropriate for gestational age (AGA), to establish cut-off values for CIMT in obese pediatric populations. Subjects and methods: A cross-sectional study was carried out over a 1-year period (Jul 2013 - June 2014). We analyzed 122 obese patients aged $4-20$ (mean age $14.9 \pm 2.28$ ). Twenty-six patients were born SGA. CIMT was measured in all the patients. Using ROC curve, cut-off values were obtained for both groups. Results: We demonstrated a correlation between CIMT and adiponectin, leptin and high sensitivity C-reactive protein ( $h$ sCRP) $(r=-0.25, r=0.279, r=0.498)$ in obese children. CIMT in obese children born SGA were significantly increased as compared with obese children born AGA of similar age, sex and body mass index (BMI) $(p=0.0035)$. A CIMT cut off value of $0.049 \mathrm{~cm}$ has been obtained with a high sensitivity and specificity. Conclusion: CIMT is a well-known marker of subclinical atherosclerosis and its measurement is a noninvasive and inexpensive method of detecting subclinical atherosclerosis. Being born SGA increases the atherogenic risk. Obese children with CIMT above $0.049 \mathrm{~cm}$ should be screened for metabolic syndrome (MetS). Arch Endocrinol Metab. 2017;61(1):14-20
\end{abstract}

\section{INTRODUCTION}

IMT provides an index of atherosclerosis in other vascular regions (1-5) and has been shown to be associated with most risk factors for atherosclerosis (6-8). Increased values of CIMT determined by B-mode ultrasound have been shown to be directly associated with an elevated risk of myocardial infarction and stroke in older adults without a previous history of cardiovascular disease (9). Thus, CIMT has been proposed as a risk factor that may be included in the algorithms for cardiovascular risk assessment (9).

The pathogenesis of atherosclerosis as identified by the Pathobiological Determinants of Atherosclerosis in Youth trial has endothelial dysfunction as its first step; an accumulation of modified lipoproteins cause a thickening of the intima; macrophages attach to the lipoproteins, resulting in the formation of foam cells, which accumulate in the intima forming a fatty streak; this step is followed by proliferation of smooth muscle cells, developing a fibrous area (10). Atherosclerotic modifications of blood vessels start in childhood, although clinical manifestations of atherosclerosis mainly occur in adults. In children and adolescents, atherosclerosis can present itself as a diffuse thickening of the intima-media space rather than the common structure of fatty streaks and fibrous capsules (11).

CIMT is commonly used as a marker of atherosclerosis; a predictive association with cardiovascular disease has been established. In adults, CIMT $>0.9 \mathrm{~mm}$ has been shown as a marker of cardiovascular risk caused by atherosclerosis (12). In children, there are few data regarding reference values for CIMT.

Adipose tissue is an important endocrine organ that produces interleukin-6 (IL-6), tumor necrosis factor alpha (TNF- $\alpha$ ), plasminogen activator inhibitor- 1 and adipokines (leptin and adiponectin). Adipokines control 
energy homeostasis and are involved in metabolic, endocrine and immunological processes.

Leptin is a hormone closely linked to adipose tissue and its levels are directly influenced by the amount of body fat mass and size of individual adipocytes; through its actions on the medial and lateral hypothalamus, it controls food intake and energy expenditure. In obesity, however, it was observed that high levels of leptin do not reduce appetite; a possible explanation may be a state of leptin resistance. It also has a pro-inflammatory action, stimulating the secretion of IL- 6 and TNF- $\alpha(13,14)$.

Adiponectin, as opposed to leptin, is a hormone inversely correlated with body fat mass. Adiponectin is the most abundant of the adipokines and is an insulinsensitizing hormone with anti-inflammatory, antiatherogenic and anti-diabetic properties $(15,16)$.

High sensitivity C-reactive protein (hsCRP) is a biomarker of the low grade chronic inflammation associated with atherosclerosis. Likewise, CRP is one of the most important inflammatory markers in obesity. Several studies showed that hsCRP is a strong independent predictor of cardiovascular risk. It has a role at different phases of atherosclerosis (17). Adults with hsCRP above $0.3 \mathrm{mg} / \mathrm{dL}$ have twice the risk of atherosclerosis compared to those with low levels $(<0.1 \mathrm{mg} / \mathrm{dL})(18,19)$. There are also studies indicating the utility of hsCRP in assessing cardiovascular risk in obese children (20).

Chronic inflammation in obesity leads to endothelial dysfunction, followed by further atherosclerotic modifications of blood vessels.

Children and adolescents with risk factors such as obesity, dyslipidemia, high blood pressure and impaired glucose metabolism are at risk for atherosclerosis in adulthood (21-23). Childhood obesity correlates with early onset of cardiovascular disease in adults. Children born small for gestational age (SGA) have a high risk of developing MetS with all its components.

This study aimed to investigate the relationship between markers of adiposity, like leptin, adiponectin, hsCRP and CIMT in obese children, to compare values of CIMT and markers of adiposity between children born SGA and AGA, and to establish cut off values for CIMT in obese pediatric populations.

\section{SUBJECTS AND METHODS}

A cross-sectional study was conducted over a period of 1 year, between July 2013 and June 2014, on cases of obesity in children diagnosed at the Emergency Hospital for Children "Louis Ţurcanu" Timişoara, in the departments of Diabetes and Nutritional Diseases, Endocrinology and Cardiology.

Subjects were considered obese on the basis of age-specific BMI reference guidelines from Centers for Disease Control and Prevention Child Growth Standards 2000 (above $95^{\text {th }}$ percentile) (24). When defining SGA, growth nomograms and charts proposed by Niklasson and cols. (25) were used; subjects whose birth weight was more than 2 standard deviations (SD) below the average for gestational age were considered SGA; subjects with birth weight within normal range for gestational age were defined as AGA.

CIMT was measured by B-mode ultrasound using a $10-\mathrm{MHz}$ linear transducer (General Electric). The subjects were examined in the supine position with the neck extended and the probe in the antero-lateral position. All measurements of CIMT were made in the longitudinal plane at the point of maximum thickness on the far wall of the right common carotid artery along a $\mathrm{l} \mathrm{cm}$ section of the artery proximal to the carotid bulb. CIMT was defined as the distance between the intimablood interface and the adventitia-media junction. After freezing the image, measurements were made using electronic calipers. The maximal thicknesses of the intima-media width were measured to give three readings and the mean value was used for statistical purposes.

hsCRP was determined by immunonephelometry from serum samples and processed in a BN ProSpec ${ }^{\circledR}$ system (Siemens Healthcare Diagnostics Inc.) (undetected if $<0.02 \mathrm{mg} / \mathrm{dL}$ ).

Quantitative measurements of serum leptin and adiponectin levels were performed using commercially available enzyme-linked immunosorbent assay kits (Antisel and Diamedix).

Exclusion criteria were evidenced for endocrine or syndromal disorders of obesity, systemic disease or acute illness.

We analyzed 122 patients diagnosed with obesity: 96 patients born AGA and 26 patients born SGA. Both groups were matched for age, sex and BMI. CIMT was also measured in members of a control group of 42 nonobese patients matched for age, sex and birth weight with the obese group (SGA+AGA).

The data are expressed as means \pm standard deviation or as frequencies. Statistical analysis was performed with MedCalc. Pearson's correlation was used to establish 
correlations between the parameters in the study group. A $p<0.05$ was considered statistically significant. ROC curve was used for determining the optimal cut-off value for CIMT in obese children.

Consent was obtained from the parents and the Ethical Committee of the hospital.

\section{RESULTS}

CIMT values measured in the nonobese group were significantly lower than those in the obese group $(0.035$ $\mathrm{cm}$ vs $0.046 \mathrm{~cm}, \mathrm{p}<0.01$ ) as shown in Table 1 .

The anthropometric and metabolic characteristics and CIMT values of the obese group are shown in Table 2.

The SGA group had significantly higher levels of leptin and hsCRP $(\mathrm{p}=0.036, \mathrm{p}=0.017$, respectively) and lower levels of adiponectin $(\mathrm{p}=0.04)$. CIMT was significantly increased in the SGA group (mean $0.057 \mathrm{~cm}$ vs $0.043 \mathrm{~cm}$ ) (Figure 1 ); there were significant differences between the two groups $(\mathrm{p}=0.0035)$.

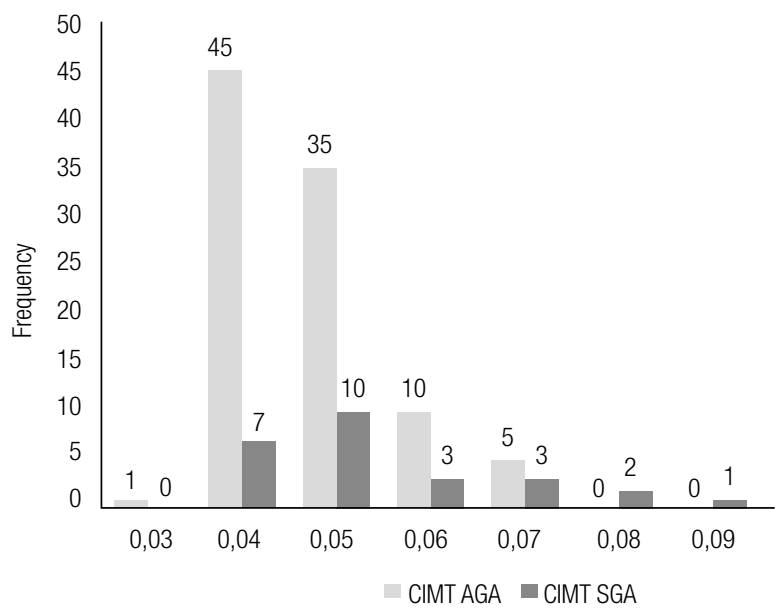

Figure 1. CIMT histogram in SGA and AGA group.

Table 1. The anthropometric characteristics and CIMT values of the nonobese group and of the obese group

\begin{tabular}{|c|c|c|c|c|c|c|c|}
\hline \multirow[t]{2}{*}{ Total number } & \multicolumn{3}{|c|}{$\begin{array}{l}\text { Obese group (SGA+AGA) } \\
122\end{array}$} & \multicolumn{3}{|c|}{$\begin{array}{c}\text { Non obese group } \\
42\end{array}$} & \multirow[t]{2}{*}{$P$ value } \\
\hline & Mean & SD & Range & Mean & SD & Range & \\
\hline Age (years) & 14.9 & 2.3 & $4-20$ & 14.5 & 2.48 & $4-18$ & 0.68 \\
\hline Birth weight (grams) & 3231.72 & 610 & $970-4300$ & 3032.87 & 388.31 & $2350-3800$ & 0.57 \\
\hline Sex (\%) & & & & & & & 0.68 \\
\hline Male & & $40.3 \%$ & & & $36.5 \%$ & & \\
\hline Female & & $59.7 \%$ & & & $63.5 \%$ & & \\
\hline Antropometric data BMl $\left(\mathrm{kg} / \mathrm{m}^{2}\right)$ & 32.8 & 7.27 & $19-54.5$ & 16.09 & 3.31 & $7.43-21.85$ & $<0.01$ \\
\hline CIMT (cm) & 0.046 & 0.01 & 0.03-0.09 & 0.035 & 0.005 & $0.025-0.05$ & $<0.01$ \\
\hline
\end{tabular}

BMI: body mass index; CIMT: carotid intima media thickness.

Table 2. Anthropometric and metabolic characteristics and CIMT values of AGA versus SGA group

\begin{tabular}{|c|c|c|c|c|c|c|c|}
\hline \multirow[t]{2}{*}{ Total number } & \multicolumn{3}{|c|}{$\begin{array}{l}\text { Obese SGA-group I } \\
26\end{array}$} & \multicolumn{3}{|c|}{$\begin{array}{l}\text { Obese AGA-group II } \\
96\end{array}$} & \multirow[t]{2}{*}{$P$ value } \\
\hline & Mean & SD & Range & Mean & SD & Range & \\
\hline Age (years) & 14.41 & 3.3 & $5-17$ & 15.05 & 2.28 & $4-20$ & 0.22 \\
\hline Birth weight (grams) & 2550 & 403.5 & $970-2860$ & 3446.25 & 461.4 & $2400-4300$ & $<0.01$ \\
\hline Gestational age (weeks) & 38 & 2.9 & $30-41$ & 39.368 & 1.14902 & $34-41$ & 0.025 \\
\hline \multicolumn{8}{|l|}{$\operatorname{Sex}(\%)$} \\
\hline Male & & $42.3 \%$ & & & $36.5 \%$ & & \\
\hline Female & & $57.7 \%$ & & & $63.5 \%$ & & 0.78 \\
\hline Residence urban/rural & & $57 \% / 43 \%$ & & & $60 \% / 40 \%$ & & 0.79 \\
\hline Antropometric data BMI $\left(\mathrm{kg} / \mathrm{m}^{2}\right)$ & 29.6 & 8.13 & $19-54.5$ & 30.6 & 6.3 & $17-47$ & 0.5 \\
\hline CIMT (cm) & 0.057 & 0.008 & $0.04-0.09$ & 0.043 & 0.008 & $0.03-0.07$ & $<0.01$ \\
\hline Biological data Leptin (ng/mL) & 29.5 & 14.23 & $15.2-43.7$ & 26 & 13.08 & $12.9-39.1$ & 0.036 \\
\hline Adiponectin (ug/mL) & 16.4 & 2.27 & $1-48$ & 19.9 & 2.34 & $2.4-64$ & 0.04 \\
\hline hsCRP (mg/dL) & 0.9 & 0.24 & $0.6-1.1$ & 0.7 & 0.32 & $0.39-1$ & 0.017 \\
\hline
\end{tabular}

BMI: body mass index; CIMT: carotid intima media thickness; hSCRP: high sensitive $\mathrm{C}$ reactive protein. 


\section{The relationship between CIMT and adypokines}

We further aimed to determine correlations between CIMT and the other variables.

CIMT was directly weakly correlated with leptin $(\mathrm{r}=0.279 ; \mathrm{p}<0.05)$ and strongly with hsCRP $(\mathrm{r}=0.498 ; \mathrm{p}=0.01)$, and inversely and weakly correlated with adiponectin $(\mathrm{r}=-0.25 ; \mathrm{p}=0.04)$ (Table 3$)$.

Table 3. Correlation between CIMT and other variables

\begin{tabular}{lccc}
\hline & Leptin & Adiponectin & hsCRP \\
\hline CIMT Pearson's correlation & 0.279 & -0.25 & 0.498 \\
$\mathrm{p}$ & 0.01 & 0.04 & 0.031 \\
\hline
\end{tabular}

hs-CRP: high-sensitivity C-reactive protein.

\section{Establishing cut-off values using ROC curve in obese children}

We have determined cut-off values for the SGA group using ROC curve (Figure 2). The limited size of the SGA sample (26 patients) compelled us to establish a cut-off value using CIMT measurements from both groups (Figure 3). This cut-off value of CIMT acts as a designated limit; higher values indicate an increased risk of developing MetS.

Using ROC curve, we obtained for the obese group a cut-off CIMT value of $0.049 \mathrm{~cm}$ with a sensitivity of $100 \%$ and a specificity of $84 \%$.

\section{DISCUSSION}

Previous reports indicate that the presence of obesity in childhood is associated with increased adult CIMT $(22,23)$. CIMT is a well-known marker of subclinical atherosclerosis and it can also indicate future cardiocerebrovascular disease (26-28).

In a recent study, we demonstrated a relationship between CIMT, MetS and its components in obese children (29).

Obesity is a chronic inflammatory disorder in which leptin, adiponectin and CRP play an important role (30). In this study, a correlation between CIMT adiponectin, leptin and hsCRP was observed. In healthy individuals, adiponectin has anti-atherogenic properties and studies have shown that, in adults, a low level of adiponectin correlates with coronary lesions and is an independent risk factor for the progression of type 2 diabetes $(31,32)$. Previous research suggests that elevated leptin levels are involved in cardio-cerebrovascular disorders such as myocardial infarction and stroke (33).

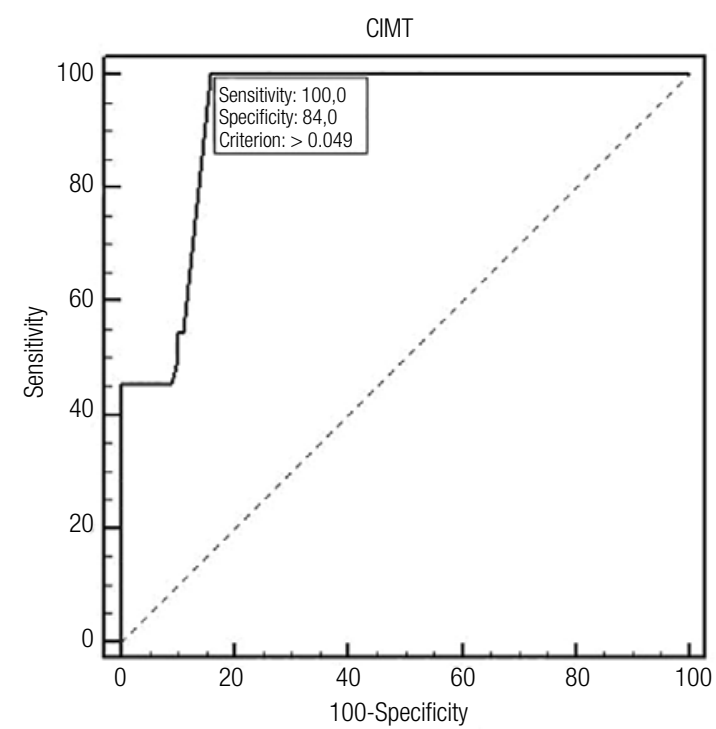

Figure 2. ROC curve SGA group.

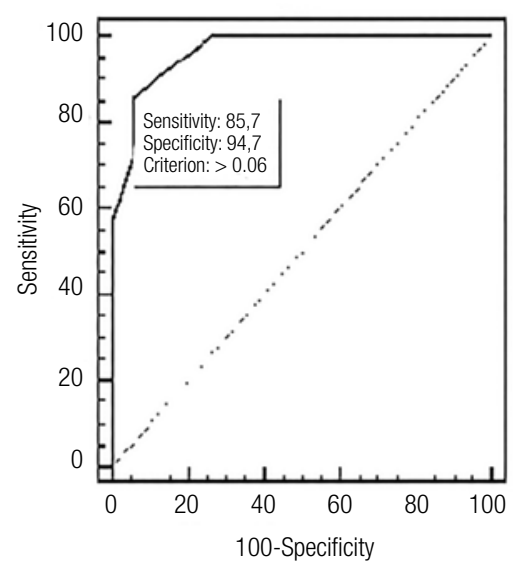

Figure 3. ROC curve $S G A+A G A$ groups.

Leptin induces smooth muscle cell hypertrophy and proliferation through endothelin- 1 and angiotensin II dependent mechanisms (34). Angiotensin II increases the production of reactive oxygen species and induces the release of the vasoconstrictor endothelin-1 $(35,36)$. Leptin also stimulates the secretion of inflammatory markers such as CRP, TNF- $\alpha$ and IL- 6 , which are directly involved in the development of endothelial dysfunction and atherosclerosis $(37,38)$.

Winer and cols. established that low levels of adiponectin are associated with higher CRP levels (39). Also, a direct correlation between CIMT and leptin was demonstrated in obese individuals (40). The weak correlation between CIMT, adiponectin 
and leptin detected in our study was an indicator of further cumulative risk factors leading to changes in CIMT values. A stronger correlation has been observed between CIMT and hsCRP, suggesting an inflammatory process in obesity. Endothelial dysfunction is considered the earliest step in the atherosclerotic process and precedes any morphological changes in the walls of blood vessels.

The catch-up growth in children born SGA has been associated with a high risk of developing MetS with all its components: obesity, impaired glucose tolerance, insulin resistance with subsequent development of diabetes, arterial hypertension and dyslipidemia. There is also a risk of developing adrenal and reproductive disorders (41). These changes have been related to intrauterine life environments and linked to epigenetic fetal programming.

Visentin and cols., in a study examining relationships between levels of adipokines (adiponectin and leptin), inflammatory markers (CRP, TNF- $\alpha$ and IL-6) and vascular remodeling in pregnancies with intrauterine growth restriction, found higher CIMT values, high serum concentrations of proinflamatory cytokines (leptin, hsCRP, TNF- $\alpha$ and IL-6) and low levels of adiponectin in fetuses (42).

In our study, there was a significant statistical difference between AGA and SGA groups regarding CIMT, adiponectin, leptin and hsCRP as shown in Table 1.

Reference values for CIMT in adults are $0.04-0.07 \mathrm{~cm}$ (43). An increase in CIMT with each decade of age $(0.066 \mathrm{~cm} /$ decade $)$ was observed, with CIMT values as high as $0.0733 \mathrm{~cm}$ in the $70-79$ years group (44). An increase of $0.1 \mathrm{~mm}$ in CIMT is known to raise the risk of myocardial infarction by $11 \%(45)$.

In children, there are very few studies on CIMT;

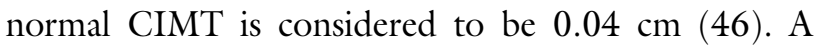
study assessing CIMT in children aged 6-14 found a median CIMT of $0.048 \mathrm{~cm}$ in nonobese children and $0.055 \mathrm{~cm}$ in obese children (47). Another study, which enrolled 128 patients aged 6-18 years, showed a CIMT of $0.043 \mathrm{~cm}$ in nonobese children versus $0.051 \mathrm{~cm}$ in obese children (48). In our control group - the nonobese group - we obtained a median CIMT value as low as $0.035 \mathrm{~cm}$. A significant difference from previous results can be clearly observed. An explanation might be the number of adolescents enrolled in the study group; as we know, CIMT value increases with age.
We found little literature data regarding reference values for CIMT in obese children; with this study we achieved threshold values of CIMT maintaining high sensitivity and specificity. For both groups we obtained a cut-off value of $0.049 \mathrm{~cm}$, with a sensitivity of $100 \%$ and a specificity of $84 \%$.

It is our belief that these cut-off CIMT values for assessing metabolic risk are "pilot" results. In order to refine these values and offer a reliable tool for determining cardiovascular risk in obese children, further extensive population studies are recommended.

\section{Limitation}

Data from our small clinical samples and the limited number may not be representative for general populations. CIMT may also be influenced by other risk factors that have not been tested in our study.

\section{CONCLUSION}

CIMT is a well-known marker of subclinical atherosclerosis and its measurement is a noninvasive and inexpensive method of detecting subclinical atherosclerosis; it is in relationship to adiponectin, leptin and hsCRP. Being born SGA increases the atherogenic risk. Obese children having CIMT $>0.049 \mathrm{~cm}$ should be tested for MetS. Further population studies that look into CIMT values in obese and nonobese children are necessary.

Acknowledgments: this research was supported by a grant at University of Medicine and Pharmacy "Victor Babes" Timisoara PII-C2-TC-2014 ChildObesity-2014 obtained by Ramona Stroescu.

Disclosure: no potential conflict of interest relevant to this article was reported.

\section{REFERENCES}

1. Craven TE, Ryu JE, Espeland MA, Kahl FR, McKinney WM, Toole $\mathrm{JF}$, et al. Evaluation of the association between carotid artery atherosclerosis and coronary artery stenosis: a case-control study. Circulation. 1990;82:1230-42.

2. Wendelhag I, Wiklund O, Wilkstrand J. Atherosclerotic changes in the femoral and carotid arteries in familial hypercholesterolemia. ArteriosclerThromb. 1993;13:1404-11.

3. Burke GL, Evans GW, Riley WA, Sharrett AR, Howard G, Barnes $\mathrm{RW}$, et al. Arterial wall thickness is associated with prevalent cardiovascular disease in middle aged adults: the Atherosclerosis Risk in Communities (ARIC) Study. Stroke. 1995;26:386-91.

4. Allan PI, Mowbray PI, Lee AJ, Fowkes FGR. Relationship between carotid intima-media thickness and symptomatic and 
asymptomatic peripheral arterial disease: the Edinburgh Artery Study. Stroke. 1997;28:348-53.

5. Bots ML, Hoes AW, Koudstaal PJ, Hofman A, Grobbee DE. Common carotid intima-media thickness and risk of stroke and myocardial infarction: the Rotterdam Study. Circulation. 1997;96:1432-7.

6. Ebrahim S, Papacosta O, Whincup P, Wannamethee G, Walker $M$, Nicolaides $A N$, et al. Carotid plaque, intima media thickness, cardiovascular risk factors, and prevalent cardiovascular disease in men and women: the British Regional Heart Study. Stroke. 1999;30:841-50.

7. Howard G, Manolio TA, Burke GL, Wolfson SK, O'Leary DH. Does the association of risk factors and atherosclerosis change with age? An analysis of the combined ARIC and CHS cohorts. Stroke. 1997;28:1693-701.

8. Mannami T, Konishi M, Baba S, Nishi N, Terao A. Prevalence of asymptomatic carotid atherosclerotic lesions detected by high resolution ultrasonography and its relation to cardiovascular risk factors in the general population of a Japanese city: the Suita Study. Stroke. 1997;28:518-25.

9. O'Leary DH, Polak JF, Kronmal RA, ManolioTA, Burke GL, Wolfson SK Jr. Carotid-artery intima media thickness as a risk factor for myocardial infarction and stroke in older adults. $\mathrm{N}$ Engl $\mathrm{J}$ Med. 1999;340:14-22.

10. McGill HC Jr, McMahan CA, Zieske AW, Malcom GT, Tracy RE, Strong JP. Effects of nonlipid risk factors on atherosclerosis in youth with a favorable lipoprotein profile. Pathobiological Determinants of Atherosclerosis in Youth (PDAY) Research Group. Circulation. 2001;103(11):1546-50.

11. Groner JA, Joshi M, Bauer JA. Pediatric precursors of adult cardiovascular disease: noninvasive assessment of early vascular changes in children and adolescents. Pediatrics. 2006;118(4):168391.

12. Amato $M$, Montorsi $P$, Ravani A. Carotid intima-media thickness by B-mode ultrasound as surrogate of coronary atherosclerosis: correlation with quantitative coronary angiography and coronary intravascular ultrasound findings. Eur Heart J. 2007;28:2094-101.

13. Anubhuti, Arora S. Leptin and its metabolic complications-an update. Infam. 2008;10:973-93.

14. Meyers MG, Cowley MA, Munzberg H. Mechanisms of leptin action and leptin resistance. Annu Rev Physiol. 2008;70:537-56.

15. Shehzad A, lqbal W, Shehzad O, Lee YS. Adiponectin: regulation of its production and its role in human diseases. Hormones. 2012;11:8-20.

16. Aprahamian TR, Sam F. Adiponectin in cardiovascular inflammation and obesity. Int J Infam. 2011;2011:376909.

17. Montero D, Walther G, Perez-Martin A. Endothelial dysfunction, inflammation, and oxidative stress in obese children and adolescents: markers and effect of lifestyle intervention. Obesity Rev. 2012;13:441-55.

18. Ridker PM. High-sensitivity C-reactive protein: potential adjunct for global risk assessment in the primary prevention of cardiovascular disease. Circulation. 2001;103:1813-8.

19. PearsonTA, Mensah GA, Alexander RW, Anderson JL, Cannon RO 3rd, Criqui $\mathrm{M}$, et al. Markers of inflammation and cardiovascular disease: application to clinical and public health practice. A statement for healthcare professionals from the Centers for Disease Control and Prevention and the American Heart Association. Circulation. 2003;107:499-511.

20. Soriano-Guilén L, Hernández-Garcia B, Pita J, Domínguez-Garrido N, Del Río-Camacho G, Rovira A. High-sensitivity C-reactive protein is a good marker of cardiovascular risk in obese children and adolescents. Eur J Endocr. 2008;159:R1-4.
21. Roede MJ, Van Wieringen JC. Growth diagrams 1980. Netherlands third nation-wide survey, Tijdschrift voor Sociale Gezondheidszorg. 1985;63(suppl):1-34.

22. Davis PH, Dawson JD, RileyWA, Lauer RM. Carotid intimal-medial thickness is related to cardiovascular risk factors measured from childhood through middle age:The Muscatine Study. Circulation. 2001;104:2815-9.

23. Raitakari OT, Juonala $M$, Kähönen $M$, Taittonen $L$, Laitinen T, MäkiTorkko N, et al. Cardiovascular risk factors in childhood and carotid artery intima-media thickness in adulthood: the Cardiovascular Risk in Young Finns Study. JAMA. 2003;290:2277-83.

24. National Center for Health Statistics, Centers for Disease Control and Prevention growth charts: United States National Center for Health Statistics, Hyattsville, MD, United States, 2000. Avaliable from www.cdc.gov/growthcharts.

25. Niklasson A, Ericson A, Fryer JG, Karlberg J, Lawrence C, Karlberg P. An update of the Swedish reference standards for weight, length and head circumference at birth for given gestational age (1977-1981). Acta Paediatr Scand. 1991;80(8-9):756-62.

26. Li S, Chen W, Srinivasan SR, Bond MG, Tang R, Urbina EM, et al. Childhood cardiovascular risk factors and carotid vascular changes in adulthood the Bogalusa Heart Study. JAMA. 2003;290:2271-6.

27. Csiba L. Carotid intima-media thickness measured by ultrasonography: effect of different pharmacotherapies on atherosclerosis progression. Orv Hetil. 2005;146:1239-44.

28. Reinehr T, Kiess W, de Sousa G, Stoffel-Wagner B, Wunsch R. Intima media thickness in children obesity relations to inflammatory marker, glucose metabolism, and blood pressure. Metabolism. 2006:55:113-8.

29. Stroescu R, Micle I, Marginean O, Bizerea T, Marazan M, Puiu $M$, et al. Is small for gestational age status associated with an increased risk of atherogenesis? Maedica. 2013;8:315-20.

30. Li J, Li F, Zhao A. Inflammation and leptin. Met Dis. 2006;3:387-93.

31. Kumada $M$, Kihara $S$, Sumitsuji $S$, Kawamoto $T$, Matsumoto $S$, Ouchi N, et al. Association of hypoadiponectinemia with coronary artery disease in men. Arterioscler Thromb Vasc Biol. 2003;23:859.

32. Winer JC, Zern TL, Taksali SE, Dziura J, Cali AM, Wollschlager M, et al. Adiponectin in childhood and adolescent obesity and its association with inflammatory markers and components of the metabolic syndrome. J Clin Endocrinol Metab. 2006;91:4415-23.

33. Beltowski J. Leptin and atherosclerosis. Atherosclerosis. 2006;189:47-60

34. Zeidan A, Purdham DM, Rajapurohitam V, Javadov S, Chakrabarti $\mathrm{S}$, Karmazyn M. Leptin induces vascular smooth muscle cell hypertrophy through angiotensin II-and endothelin-1-dependent mechanisms and mediates stretch-induced hypertrophy. J Pharmacol ExpTher. 2005;315:1075-84.

35. Yanagitani $Y$, Rakugi $H$, Okamura A, Moriguchi K, Takiuchi $S$, Ohishi $\mathrm{M}$, et al. Angiotensin II type 1 receptor-mediated peroxide production in human macrophages. Hypertension. 1999;33:33539.

36. Imai T, Hirata $Y$, Emori T, Yanagisawa M, Masaki T, Marumo F Induction of endothelin-1gene by angiotensin and vasopressin in endothelial cells. Hypertension. 1992;19:753-7.

37. Koh KK, Quon MJ, Lee SJ, Han SH, Ahn JY, Kim JA, et al. Efonidipine simultaneously improves blood pressure, endothelial dysfunction, and metabolic parameters in non-diabetic patients with hypertension. Diabetes Care. 2007;30:1605-7.

38. Loffreda S, Yang SQ, Lin HZ, Karp CL, Brengman ML, Wang DJ, et al. Leptin regulates proinflammatory immune responses. FASEB J. 1998:12:57-65. 
39. Winer JC, Zern TL, Taksali SE, Dziura J, Cali AMG, Wollschlager $M$, et al. Adiponectin in childhood and adolescent obesity and its association with inflammatory markers and components of the metabolic syndrome. J Clin Endocrinol Metab. 2006;91:4415-23.

40. Ciccone M, Vettor R, Pannacciulli N, Minenna A, Bellacicco M, Rizzon $\mathrm{P}$, et al. Plasma leptin is independently associated with the intima-media thickness of the common carotid artery. Int $\mathrm{J}$ Obes Relat Metab Disord. 2001;25:805-10.

41. Reinehr T, Kleber M, Toschke A. Small for gestational age (SGA) status is associated with metabolic syndrome in over-weight children. Eur J Endocrinol. 2009;20:1-19.

42. Visentin S, Lapolla A, Londero AP, Cosma C, Dalfrà M, Camerin M, et al. Adiponectin levels are reduced while markers of systemic inflammation and aortic remodelling are increased in intrauterine growth restricted mother-child couple. Biomed Res Int. 2014;401595.

43. Mahmoud MZ. Sonography of common carotid arteries' intima: media thickness in the normal adult population in Sudan. $\mathrm{N} \mathrm{Am} \mathrm{J}$ Med Sci 2013;5(2):88-94.
44. Beşir FH, Yazgan S, Celbek G, Aydın M, Yazgan O, Erkan ME, et al. Normal values correlates' of carotid intima-media thickness and affecting parameters in healthy adults. Anadolu Kardiyol Derg. 2012;12(5):427-33.

45. Bots ML, Hoes AW, Koudstaal PJ, Hofman A, Grobbee DE. Common carotid intima-media thickness and risk of stroke and myocardial infarction: the Rotterdam Study. Circulation. 1997;96: 1432-7.

46. Reinehr T, Wunsch R, Pütter C, Scherag A. Relationship between Carotid Intima-Media Thickness and Metabolic Syndrome in Adolescents. J Pediatr. 2013;163(2):327-32.

47. Iannuzzi A, Licenziati MR, Acampora C, Salvatore V. Increased carotid intima-media thickness and stiffness in obese children. Diabetes Care. 2004;27(10):2506-8.

48. Stabouli S, Kotsis V, Karagianni C, Zakopoulos N, Konstantopoulos A. Blood pressure and carotid artery intima-media thickness in children and adolescents: the role of obesity. Hellenic J Cardiol. 2012;53(1):41-7. 